\title{
THE EFFECT OF TWO PACKING TECHNIQUES ON ADAPTATION OF RESIN DENTURE BASE MATERIALS
}

\author{
Ehab M. Aboelroos* and Amr A. Rady**
}

\begin{abstract}
Background: Acrylic resin denture bases undergo dimensional changes during polymerization. Injection molding techniques are reported to reduce these changes and thereby improve physical properties and adaptation of denture bases. The aim of this study was to compare denture baseadaptation processed by conventional and injection-molding techniques.

Materials and Methods: Twenty one accurate denture bases with the same dimension were fabricated and divided into three groups. For the first group, sevenpolymethyl methacrylate denture bases were made using conventional compression moulding technique and for the other two groups, two different injection mouldingunits were used to produce seven polyamide bases (thermo-plasticized) and seven polymethyl-methacrylate (PMMA) bases (themo-polymerized). The adaptation accuracy was examined using universal measuring microscope. The gap between the resin base and stone cast was measured at posterior palatal area at five points, corresponding to the right and left residual ridge crests, the midline, and the right and left marginal limits of the flanges.
\end{abstract}

Results: Injection molded bases showed significant lower total gap scores at the crest and the palate compared to the conventional compression molded ones. However, there was no statistically significant difference between both groups at the vestibular gap. Injection molded poly-amide resin denture bases showed significant difference compared to PMMA injected molded ones.

Conclusion: Injection moulded polyamide resin has superior dimensional accuracy and adaptation compared to conventional pressure packed or injection moulded PMMA resin.

\section{INTRODUCTION}

Acrylic resin innovation was a major breakthrough in 1937 that continues to have an influence on modern dentistry, ${ }^{(1)}$ due to its advantages which include good aesthetic, easy manipulation, both in the clinic and in the lab, as well as its low cost for processing ${ }^{(2)}$. However, multiple researches revealed that, regardless of the type of acrylic resin selected, the processing deformation that is apparent

\footnotetext{
* Assistant Professor of Removable Prosthodontics, Faculty of Oral and Dental Medicine, Cairo University,

** Lecturer of Removable Prosthodontics, Faculty of Oral and Dental Medicine, Cairo University.
} 
when the cured dentures are removed from the cast is universally recognized as major disadvantage of this material. ${ }^{(3)}$

It was noted that at least two unavoidable dimensional changes are active in every acrylic denture; namely, linear shrinkage of $0.3 \%-0.5 \%$, which occurs during processing, and subsequently linear expansion of $0.1 \%-0.2 \%$, which occurs upon immersion in water producing a net linear shrinkage of $0.1 \%$ to $0.4 \%{ }^{(4)}$.

The inaccuracy can affect any area causing instability and pressure points on the soft tissues, but the greatest effect of linear shrinkage is usually on the posterior palatal region of the maxillary denture, resulting in a gap between this area and the denture ${ }^{(5)}$. A close adaptation to the soft tissue is required for the retention and stability of dentures, and later on the satisfaction of the patient ${ }^{(6)}$.

For a long time, polymethyl methacrylate (PMMA) resin was polymerized using the conventional method that includes compression molding technique with heat activation in a water bath (thermo-polymerized) ${ }^{(7)}$. In an effort to overcome dimensional inaccuracies of PMMA resin, new thermoplastic resins and alternative processing techniques have been developed (8-10).

One of these techniques is the injection molding technique, which involves premeasured mechanical mixing of resin injected under continuous pressure throughout a controlled processing procedure to compensate for the expected polymerization shrinkage of the resin ${ }^{(11)}$. Several studies have revealed that injection molding techniques might result in fewer dimensional inaccuracies and more accurate denture base than conventional processing techniques. ${ }^{(12-14)}$

Polyamides, known as 'nylon' are thermoplastic polymers produced by condensation between a Diamine and a Di-basic acid; Nylon is a crystalline polymer, whereas PMMA is amorphous. This crystalline effect accounts for the lack of solubility of nylon in solvents, as well as high heat resistance and high strength coupled with ductility. It was especially used in exceptional cases like repeated denture fracture and for patients with tissue allergies against acrylic denture base or denture fractures ${ }^{(1)}$.

Therefore, the aim of this study was to compare different resin denture bases processed by conventional and injection-molding techniques on the adaptation of final denture base. The null hypothesis was that different packing techniques have no effect on adaptation of different final resin denture base materials.

\section{MATERIAL AND METHODS}

Twenty one casts were made from a silicone negative replica (Farasaco B-3 NM GOK, USA) using improved dental stone. Light curing tray plates (Vertex, Zeist, Netherland) were used to produce uniform and similar denture bases overall the casts. The casts were then divided into three groups, each group included seven casts.

Compression moulding heat cured polymethyl methacrylate denture bases (Vertex regular, Zeist, Netherland) were produced on seven casts, where the liquid-to-powder ratio of resin was $15 \mathrm{ml}$ of liquid to $34.5 \mathrm{~g}$ of powder that were mixed according to the manufacturer's recommendation and packed in the flask. Polymerization process was performed at $70^{\circ} \mathrm{C}$ for 90 minutes followed by 30 minutes at $90^{\circ} \mathrm{C}$.

Over the casts of the second group, prepolymerized (Thermo-plasticized) Thermosens capsules (Thermo-sens, Vertex, Netherland) were cured using thermoject 22 injection molding unit at temperature $290 \mathrm{C}$ and pressure 6 bars for 18 minutes and 1 minute cooling to produce polyamide denture bases.

For the third group of casts, injection molding polymethyl methacrylate bases were cured using 
thermo-press 400 injection molding unit at temperature $260 \mathrm{C}$ and 5 bars for 26 minutes (Bre Crystal (thermo-polymerized), Bredent, Germany). The curing flasks were bench-cooled to room temperature and all three groups specimens were deflasked.

All denture bases were polished on their casts with a wet rag wheel and pumice. For injection molded bases, polishing was performed after spruces and small flashes were carefully removed.

All denture base and cast sets were sectioned transversely in the posterior palatal area $5-\mathrm{mm}$ away from the posterior end of the denture base using vertical cutting machine with diamond disk (2800/3800 revolution/min WOCO 50, Jean Wirtz, $\mathrm{GmbH} \& \mathrm{Co} \mathrm{Kg}$, Germany) under water cooling.

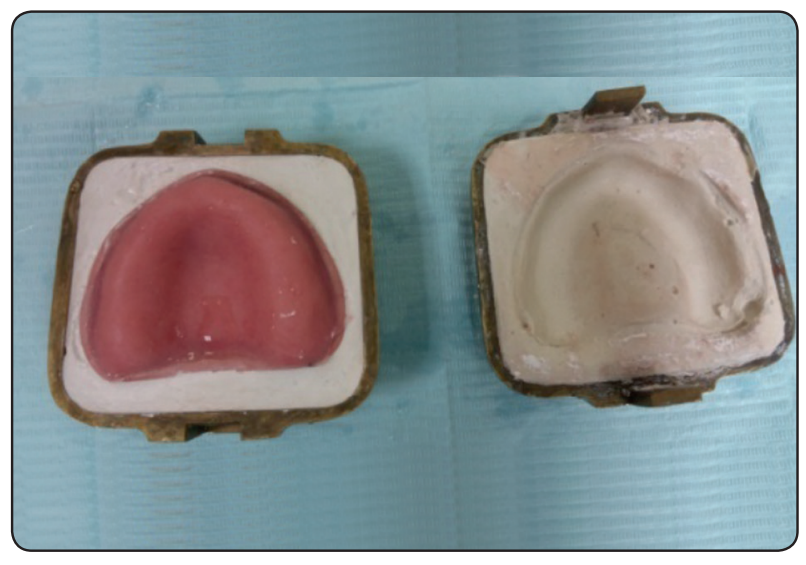

Fig. (1) Conventionally packed resin
The adaptation accuracy of the denture bases was examined using universal measuring microscope with an accuracy of $0.001 \mathrm{~mm}$ (Universal Measuring Microscope Carlzeiss \{JENA\} Resolution .001 mm Magnification 3x). The gap between the resin base and stone cast was measured at posterior palatal area at five points, corresponding to the right and left residual ridge crests $(\mathrm{C} 1, \mathrm{C} 2)$, the midline $(\mathrm{P})$, and the right and left marginal limits of the flanges(V1,V2) (deepest vestibule gap). The dimension (V), was determined from the mean of both vestibule gaps $(\mathrm{V}=(\mathrm{V} 1+\mathrm{V} 2) / 2)$, similarly the dimension, $\mathrm{C}$ was determined from the mean of both ridge crest gaps $(\mathrm{C}=(\mathrm{C} 1+\mathrm{C} 2) / 2)$.

\section{Statistical analysis}

Data waspresented as mean andstandard deviation (SD). Data wasexplored for normality using Kolmogorov-Smirnov and Shapiro-Wilk tests. Crest gap, vestibule gap and palatal gapshowed a parametric distribution, so Independent t-test wasused to compare between tested groups. One Way ANOVA was used to compare between different tested areas followed by Duncan's post hoc test for pairwise comparison when ANOVA is significant. The significance level was set at $\mathrm{P} \leq 0.05$. Statistical analysis was performed with IBM ${ }^{\circledR}$ SPSS ${ }^{\circledR}$ (SPSS Inc., IBM Corporation, NY, and USA) Statistics Version 23 for Windows.

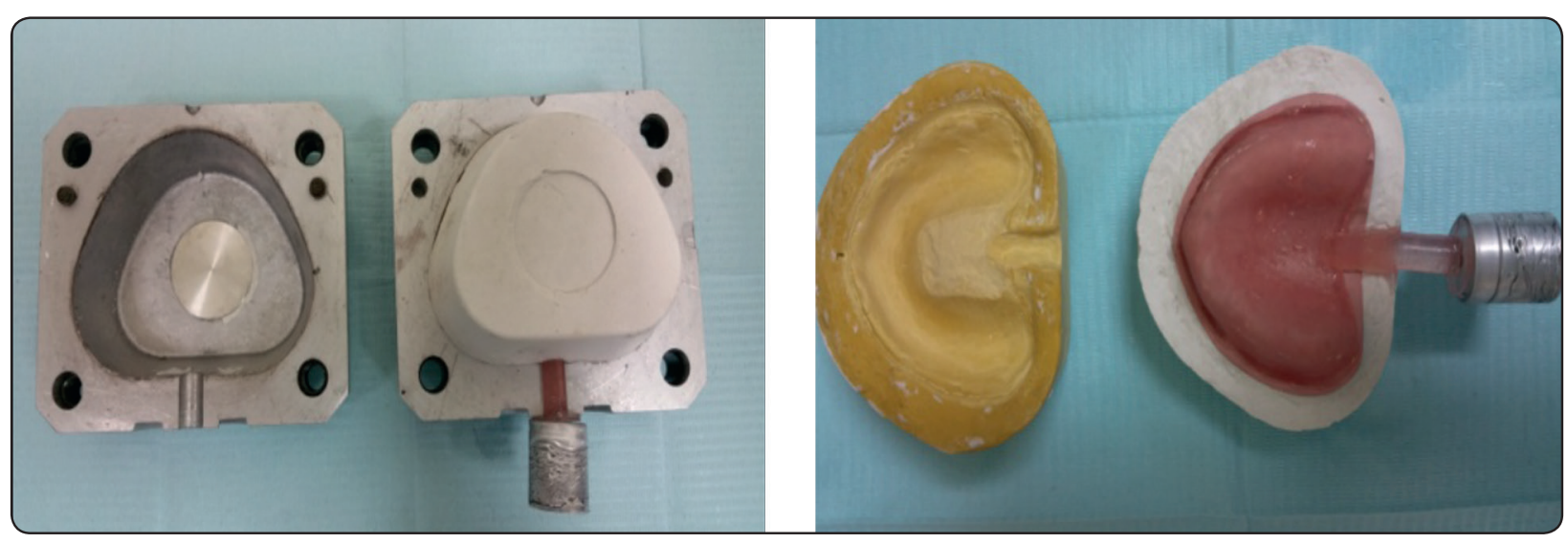

Fig. (2) Injection molded resin 


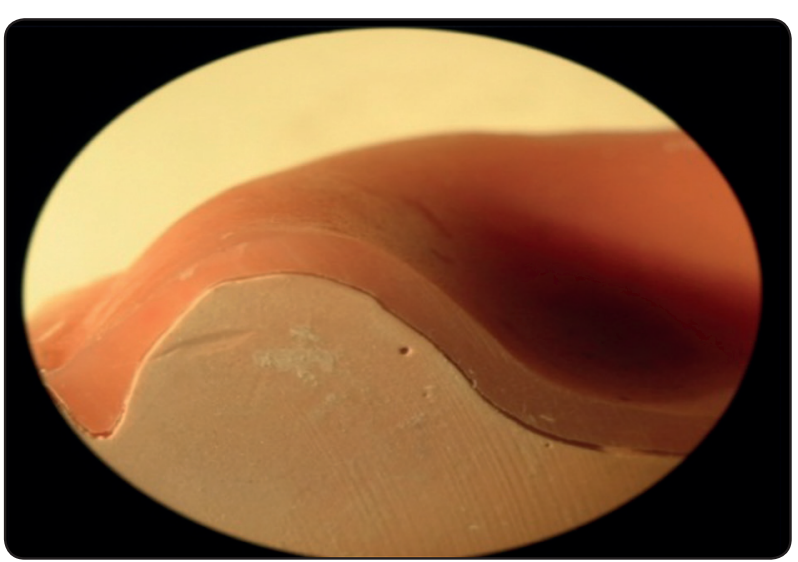

Fig. (3) Microscopic view of denture base at crest $\&$ vestibule.

\section{RESULTS}

\section{Effect of different groups\& areas on mean gap (mm)}

Mean standard deviation (SD) for different tested groups at different areas were presented in table (1$3)$ and figure $(3,4)$.

Heat cure (PMMA) resin showed an insignificant higher mean vestibulargap $(0.1564 \pm 0.1707 \mathrm{~mm})$ compared to injection molded polyamide (Vertex)

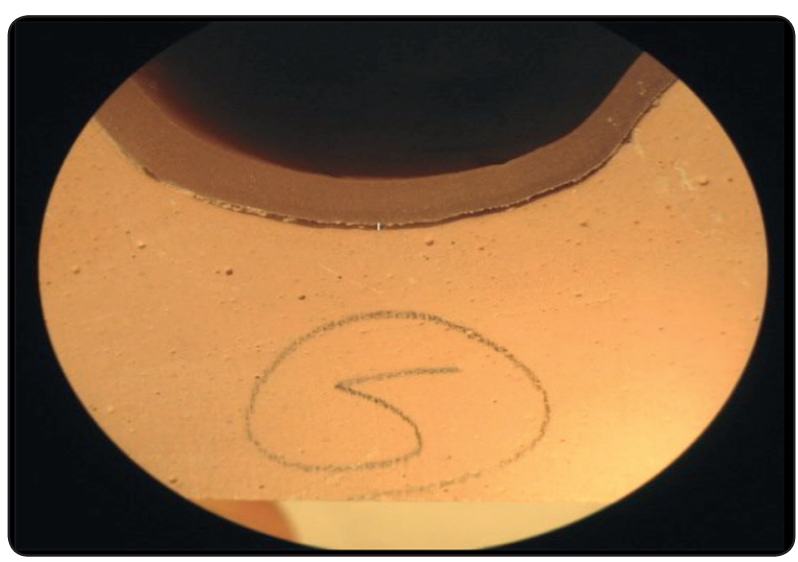

Fig. (4) Microscopic view of denture base at midpalatal area.

$(0.1118 \pm 0.1098 \mathrm{~mm})$ at $\mathrm{p}=0.468$. However, heatcure resin showed a significant higher mean crestgap $(0.2988 \pm 0.1802 \mathrm{~mm})$ compared to polyamide $(0.1199 \mathrm{~mm})$ at $\mathrm{p}=0.01$. As regards palatal gap, heat cure resin showed a significant higher mean palatal gap $(0.432 \mathrm{~mm})$ compared to polyamide $(0.194 \mathrm{~mm})$ at $\mathrm{p}=0.003$. Heat cure resin also showed a significantly higher mean total gap $(0.268 \mathrm{~mm})$ compared to injection molded polyamide (Vertex) $(0.131 \mathrm{~mm})$ at $\mathrm{p}=0.016$.

TABLE (1) Mean standard deviation (SD) of gap ( $\mathrm{mm}$ ) for different groups:

\begin{tabular}{|c|c|c|c|c|c|}
\hline & \multicolumn{2}{|c|}{$\begin{array}{c}\text { Conventional packing (PMMA) } \\
\text { VERTEX regular }\end{array}$} & \multicolumn{2}{|c|}{$\begin{array}{c}\text { Injection molded (Polyamide) } \\
\text { VERTEXThermosens }\end{array}$} & \multirow[t]{2}{*}{ P-value } \\
\hline & Mean & SD & Mean & SD & \\
\hline Crest Gap (mm) & 0.2988 & 0.1802 & 0.1199 & 0.1140 & $0.01 *$ \\
\hline Vestibule Gap (mm) & 0.1564 & 0.1707 & 0.1118 & 0.1098 & $0.468 \mathrm{NS}$ \\
\hline Palatal Gap (mm) & 0.4316 & 0.1364 & 0.1937 & 0.0429 & $0.003 *$ \\
\hline p-value & \multicolumn{2}{|c|}{$0.02 *$} & \multicolumn{2}{|c|}{$0.265 \mathrm{NS}$} & \\
\hline Total Gap (mm) & 0.2684 & 0.1085 & 0.1314 & 0.0330 & $0.016^{*}$ \\
\hline
\end{tabular}


Heat cure PMMA resin showed an insignificant higher mean vestibular gap $(0.1564 \mathrm{~mm})$ compared to injection molded PMMA (Bre-crystal) $(0.1230 \mathrm{~mm})$ at $\mathrm{p}=0.468$. However, heat cure resin showed an insignificant higher mean crest gap $(0.2988 \mathrm{~mm})$ compared to Bre-crystal (0.2320 $\mathrm{mm})$ at $\mathrm{p}=0.468$. As regards palatal gap, heat cure resin showed a significant higher mean palatal gap $(0.432 \mathrm{~mm})$ compared to Bre-crystal $(0.2137 \mathrm{~mm})$ at $\mathrm{p}=0.003$. Heat cure resin also showed a significantly higher mean total gap $(0.2684)$ compared to Brecrystal $(0.1895 \mathrm{~mm})$ at $\mathrm{p}=0.031$.
Injection molded Polyamide (Vertex) showed an insignificant mean vestibular gap $(0.1118 \mathrm{~mm})$ compared to Injection molded PMMA (Bre-crystal) $(0.1230 \mathrm{~mm})$ at $\mathrm{p}=0.433$. However, polyamide showed a significant lower mean crest gap (0.1199 $\mathrm{mm})$ compared to Bre-crystal $(0.2320 \mathrm{~mm})$ at $\mathrm{p}=0.011$. As regards palatal gap, polyamide showed an insignificantlower mean palatal gap $(0.1937 \mathrm{~mm})$ compared to Bre-crystal $(0.2137 \mathrm{~mm})$ at $\mathrm{p}=0.105$. Polyamide also showed a significantly mean total gap (0.1314) compared to Bre-crystal $(0.1895 \mathrm{~mm})$ at $\mathrm{p}=0.046$.

TABLE (2) Mean standard deviation (SD)of gap (mm) for different groups:

\begin{tabular}{|c|c|c|c|c|c|}
\hline & \multicolumn{2}{|c|}{$\begin{array}{c}\text { Conventional packing(PMMA) } \\
\text { Vertex regular }\end{array}$} & \multicolumn{2}{c|}{$\begin{array}{c}\text { Injection molded (PMMA) } \\
\text { Bre-crystal }\end{array}$} & P-value \\
& Mean & SD & Mean & SD \\
\hline Crest Gap (mm) & 0.2988 & 0.1802 & 0.2320 & 0.1114 & $0.211 \mathrm{NS}$ \\
\hline Vestibule Gap (mm) & 0.1564 & 0.1707 & 0.1230 & 0.1211 & $0.468 \mathrm{NS}$ \\
\hline Palatal Gap (mm) & 0.4316 & 0.1364 & 0.2137 & $0.003^{*}$ \\
\hline p-value & & & & $0.287 \mathrm{NS}$ & \\
\hline Total Gap (mm) & 0.2684 & $0.03 *$ & 0.1085 & 0.0556 & $0.031^{*}$ \\
\hline
\end{tabular}

TABLE (3) Mean standard deviation (SD) of gap (mm) for different groups.

\begin{tabular}{|c|c|c|c|c|c|}
\hline & \multicolumn{2}{|c|}{$\begin{array}{c}\text { Injection molded (PMMA) } \\
\text { Bre-crystal }\end{array}$} & \multicolumn{2}{|c|}{$\begin{array}{c}\text { Injection molded (Polyamide) } \\
\text { VERTEX Thermosense }\end{array}$} & \multirow{2}{*}{ P-value } \\
\hline & Mean & SD & Mean & SD & \\
\hline Crest Gap (mm) & 0.2320 & 0.1114 & 0.1199 & 0.1140 & $0.01 *$ \\
\hline Vestibule Gap (mm) & 0.1230 & 0.1211 & 0.1118 & 0.1098 & $0.433 \mathrm{NS}$ \\
\hline Palatal Gap (mm) & 0.2137 & 0.0443 & 0.1937 & 0.0429 & $0.105 \mathrm{NS}$ \\
\hline p-value & \multicolumn{2}{|c|}{$0.287 \mathrm{NS}$} & \multicolumn{2}{|c|}{$0.265 \mathrm{NS}$} & \\
\hline Total Gap (mm) & 0.1895 & 0.0556 & 0.1314 & 0.0330 & $0.046^{*}$ \\
\hline
\end{tabular}

Means with the same letter within each column indicates an insignificant difference at $p \geq 0.05 . *=$ Significant, NS=Nonsignificant 


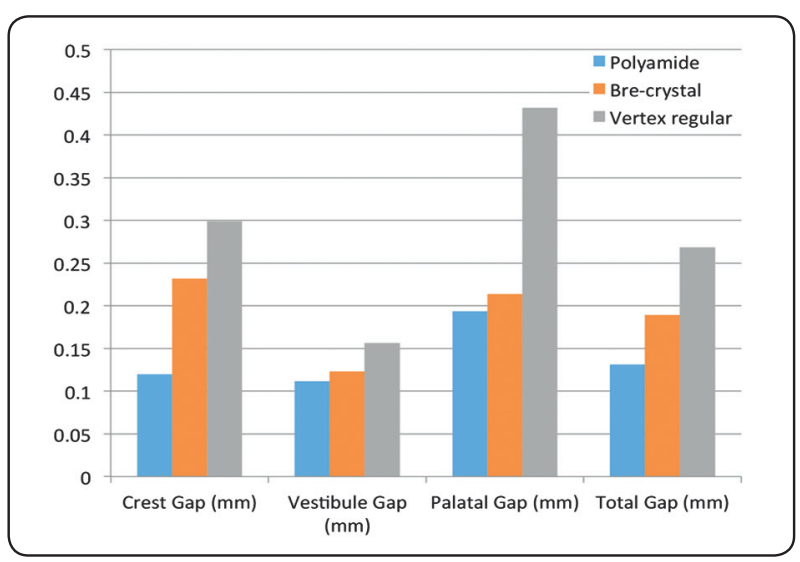

Fig. (5) Histogram showing the mean gap (mm) fordifferent groups.

\section{DISCUSSION}

Adaptation of complete denture prostheses is a fundamental factor for final prosthetic retention, proper force distribution and healthy condition of the final denture. Different factors are responsible for this adaptation, including clinical \& laboratory procedures. As regards the laboratory procedures, thicknesses of denture base, type of denture base materials, as well as packing and processing technique are considered the main guiding factors affecting final adaptation ${ }^{(15)}$.

In order to allow accurate comparison during packing for injection molded resin and conventional heat cured pressure molded acrylic denture bases, duplication of a master ready made acrylic cast into low expansion stone models using silicon duplicating materials was made. Moreover, standard thickness light-cured acrylic resin sheets were used to ensure uniform thickness of the final denture base for different packing techniques and materials. For production of the denture base, standardized steps as recommended by the manufacturers were followed regarding flasking, wax elimination, packing, processing and deflasking techniques for each group to ensure the standardization of the final results. In the same way, cutting of the casts at the same predetermined area for all groups was done under running cold water to avoid the effect of raising temperature of acrylic denture base especially for thermoplastic ones. Moreover, using magnifying measuring microscope with same magnification at the same points for all groups was followed to ensure standardized comparison. Measurements were made at 5 points to trace adaptation or gap formation at different slopes of the denture base.

The results of this study revealed in significant difference in gap formation (degree of adaptation) among the groups at the crest and the vestibular area, while these changes were significant in the mid-palatal area only, which is in accordance with many studies that indicate that dimensional changes and degree of adaptation are generally attributed to polymerization shrinkage of the resin material and a tendency of cooling shrinkage toward the central area of the denture base, as well as to subsequent distortion caused by confinement of the surface topography of the alveolar ridge ${ }^{(16-18)}$. Therefore, different gap formation was generally observed between the central portion of the posterior border, the crest of the ridge and vestibular area. Moreover, it was demonstrated that the dimensional changes of the denture base acrylic resins may be dependent on many technical factors, such as base thickness, different locations of the base and palatal geometry, which promotes critical effects in the magnitude and localization of the distortion, mainly occurring in the posterior palatal region. Thus, the distortion pattern of the base obtained in this study agrees with those of previous investigations that show the complexity of the gap formation which involves diverse and different factors. ${ }^{(19-21)}$

The significant difference observed in the total gap formation among the conventional packed and injection molded resins could be attributed to difference in packing technique and/or nature of packed material. Injection molding technique has been demonstrated in a number of researches to produce better denture base adaptation than the conventional denture processing technique, wherethese studies investigated overall base plate adaptation accuracy of denture bases produced by 
conventional pressure packing or injection molding techniques ${ }^{(8,16,22)}$. Moreover, comparative studies have demonstrated that modern injection molding techniques result in fewer dimensional inaccuracies than conventional processing techniques,as the resin is continuously injected under pressure to compensate for polymerization shrinkage. ${ }^{(17)}$

As regards the material used, the thermoplastic polyamide resins (which are not thermopolymerized resins) are characterized by complete absence of residual monomer, which results inabsence of polymerization shrinkage in the final polymerized structure. Moreover, the amide group of the polyamide resin leads toformation of crystalline structure of the final polymer rather than the amorphous structure of the PMMA resin, which in turn results in high mechanical properties of the final polymer with minimum dimensional changes and more adaptation ${ }^{(23)}$.

\section{CONCLUSION}

Injection moulded polyamide resin has superior dimensional accuracy and adaptation compared to conventional pressure packed or injection moulded PMMA resin.

\section{REFERENCES}

1. Yunus, N., A.A. Rasid, L. Azmil and M.I. Abu-Hassan, 2005. Some flexural properties of a nylon denture base polymer. Journal of Oral Rehabil., 32: 65-71

2. Pires-de-Souza, F.C., H. Panzeri, M.A. Vieira, L-F R. Garcia and S. Consani, 2009. Impact and fracture resistance of an experimental acrylic polymer with elastomer in different proportions. Mater Res., 12(4): 415-418.

3. Chen J, Lacefield W, Castleberry D. Effect of denture thickness and curing cycle on the dimensional stability of acrylic resin denture bases. Dental Materials1988;4(1):20-4.

4. Skinner E, Cooper E. Physical properties of denture resins: Part I. Curing shrinkage and water sorption. J Am Dent Assoc1943;30(6):1845-52.

5. Consani RLX, Domitti SS, Rizzatti-Barbosa CM, Consani S. Effect of commercial acrylic resins on the dimen- sional accuracy of the maxillary denture base. Braz Dent J 2002;13:57-60.

6. Turck MD, Lang BR, Wilcox DE, Meiers JC. Direct measurement of dimensional accuracy with three denture-processing techniques. Int J Prosthodont 1992;5:367-372.

7. Phoenix, R.D., M.A. Mansue, N.A. Ackerman and R.A. Jones, 2004. Evaluation of mechanical and thermal properties of commonly used denture base resins. J Prosthodont., 13: $17-27$.

8. Parvizi, A., T. Lindquist, R. Schneider, D. Williamson, D. Boyer and D. Dawson, 2004. Comparison of the Dimensional Accuracy of Injection-Molded Denture Base Materials to that of Conventional Pressure-Pack Acrylic Resin. J Prosthodont., 13(2): 83-89.

9. Keenan, P.L., D.R. Radford and R.K. Clark, 2003. Dimensional change in complete dentures fabricated by injection molding and microwave processing. J Prosthet Dent., 89(1): 37-44.

10. Ono, T., S. Kita and T. Nokubi, 2004. Dimensional Accuracy of Acrylic Resin Maxillary Denture Base Polymerized by a New Injection Pressing Method. D M J, 23(3): 348-352.

11. Young, B.C., 2010. A Comparison of Polymeric Denture Base Materials. MSc Thesis University of Glasgow.

12. Moussa A, Zaki D, El Gabry H and Ahmed T. Comparative Adaptation Accuracy of Heat Cured and Injection Molded Resin Denture Base Materials .J. Appl. Sci. Res., 8(8): 4691-4696, 2012.

13. Gharechahi J, Asadzadeh N, Shahabian F and GharechahiM 2014.Dimensional Changes of Acrylic Resin Denture Bases: Conventional Versus Injection-Molding Technique Journal of Dentistry, Tehran University of Medical Sciences July 2014; Vol. 11, No. 4

14. VigneswaranSekar, Sendhilnathan D, Lakshmi S, , Abraham A and Annapoorni. H 2015. A Comparative Evaluation of Palatal Adaptation in Denture Bases Processed With Compression Molding and Injection Molding In Two Different Palatal Configuration"-An In Vitro Study. International Journal of Scientific and Research Publications, Volume 5, Issue 7, July 2015

15. Zissis, A., R. Huggett and A. Harrison, 1991. Measurement methods used for the determination of dimensional accuracy and stability of denture base materials. J Dent., pp: 199-206. 
16. Huggett, R., A. Zissis, A. Harrison, 1992. Dimensional accuracy and stability of acrylic resin denture bases. J Prosthet Dent., 68: 634-640.

17. Nogueira, S.S., R.E. Ogle and E.L. Davis, 1999. Comparison of accuracy between compression- and injectionmolded complete dentures. J Prosthet Dent., 82: 291-300.

18. Tezvergil, A., T.A. Polat, O. Karacaer, L.V. Lassila and P.K. Vallittu, 2003. Water Sorption, Solubility and Dimensional Changes of Denture Base Polymers Reinforced with Short Glass Fibers. J Biomater Appl., 17: 321-335.

19. Latta, G.L., W.F. Bowles and J.E. Conkin, 1990. Three dimensional stability of new denture base resin in the mold processing. J Prosthet Dent., 63: 654-661.

20. Sanders, J.L., 1991. Comparison of adaptation of acrylic resin cured by microwave energy and conventional water bath. Quint Int., 22: 181-186.

21. Sykora, O. and E.J. Sutow, 1993. Posterior palatal seal adaptation: influence of processing technique, palate shape and immersion. J Oral Rehabil., 20: 19-31.

22. Ganzarolli, S.M., J.A. de Mello, R.S. Shinkai and A. Del Bel Cury, 2007. Internal adaptation and some physical properties of methacrylate-based denture base resins polymerized by different techniques. J Biomed Mater Res B Appl Biomater., 82: 169-173.

23. KohliS. and Bhatia S.:Flexural properties of polyamide versus injection-molded polymethyl methacrylate denture base materials. European Journal of Prosthodontics I SepDec 2013 | Vol 1 | Issue 3. 